www.jmscr.igmpublication.org

Impact Factor (SJIF): 6.379

Index Copernicus Value: 71.58

ISSN (e)-2347-176x ISSN (p) 2455-0450

crossref DOI: _https://dx.doi.org/10.18535/jmscr/v6i4.35

Journal Of Medical Science And Clinical Research

\title{
A comparative study to evaluate the effect of misoprostol for induction of labour at term by intravaginal versus sublingual route
}

\author{
Authors \\ Dr Rajkishori Dandotiya ${ }^{1}$, Dr Suman Kumari², Dr M Rameswar Singh ${ }^{3}$ \\ ${ }^{1}$ Senior Resident, Department of Obstetrics \& Gynaecology, G.R, Medical College, Gwalior \\ ${ }^{2}$ Senior Resident, Department of Obstetrics \& Gynaecology, Dr. S.N. Medical College Jodhpur (Raj) \\ ${ }^{3}$ Associate Professor, Department of Obstetrics \& Gynaecology, RIMS, Imphal (Manipur) \\ Corresponding Author
}

Dr Suman Kumari

Email: drsumankatewa@gmail.com

\begin{abstract}
Background: Induction of labour is defined as the process of artificial stimulation of uterine contractions before the spontaneous onset of labour. Amongst the plethora of techniques available for induction of labour, Prostaglandins remain the single most effective mean of cervical ripening and inducing labour.

Objectives: Current study was carried out to compare the efficacy of sublingual misoprostol with intravaginal misoprostol for induction of labour.

Methodology: This was a hospital based randomized prospective study conducted in the Department of Obstetrics and Gynaecology at RIMS Imphal. 462 women at term pregnancy with single live foetus having Bishop Score $\leq 6$ who required induction of labour for various indications were enrolled and randomly allocated into two groups. Group 1 received $50 \mathrm{mcg}$ misoprostol vaginally while second group received same dose of misoprostol sublingually every 4-6hourly. Outcome measures related to labour and maternal and fetal side effects were compared.

Results: There was no significant difference between both groups with regards to base line characteristic , indications for induction of labour, mean interval from the initiation of induction to the delivery, neonatal outcome and maternal complications. However significant difference was observed in Bishop Score after 4 hours and requirement of oxytocin augmentation.

Conclusion: Misoprostol can be used either sublingually or by vaginal route for induction of labour at term without any major fetal and maternal side effects.

Keywords: Induction, Labour, Misoprostol, Sublingual, Vaginal.
\end{abstract}

\section{Introduction}

Induction of labour is defined as the process of artificially stimulating the uterus to start labour ${ }^{1}$. Induction of labour is indicated when the risks associated with waiting for the spontaneous onset of labour is greater than the risks associated with shortening the duration of pregnancy by induction.
Success rate of induction mainly depends upon the state of cervix as induction of labour in unfavourable cervix may lead to prolonged labour. Various mechanical, surgical and pharmacological methods have been used as a cervical ripening agent. Prostaglandins are the most common method for cervical ripening used in a variety of 
forms, dosages and application routes ${ }^{2}$. Misoprostol, which is a synthetic PGE1 analogue, is currently used for labour induction as it is cheaper than the other PGs, easy to administer, does not require refrigeration for storage and can be administered vaginally, buccally and sublingually. Absorption by oral route is erratic at the same time it is more rapid than vaginally administered misoprostol reaching peak serum concentrations within $30 \mathrm{~min}$ compared to one hour with vaginal route. However vaginal administration may lead to uterine hyper stimulation and tachysystole by direct effects on the cervix. Various trials have been conducted but still no consensus has been achieved regarding optimal dose and route ${ }^{3-6}$. The current study was designed to compare the efficacy and safety of misoprostol administered sublingually with vaginally administered misoprostol for induction of labour.

\section{Methods}

After approval from the Institutional Ethical Committee, current hospital based prospective study was conducted at Department of Obstetrics and Gynaecology RIMS, Imphal (Manipur) over a period of one \& half years.

\section{Inclusion criteria}

1) Women with singleton term gestation (37wks-40wks)

2) Singleton pregnancy

3) Cephalic presentation

4) Unfavorable cervix (Bishop's score $<6)$

5) Reassuring fetal heart tracing

6) Absence of uterine contractions

\section{Exclusion criteria}

1. Preterm pregnancy

2. Intrauterine fetal death

3. Multiple gestation

4. Scarred uterus (previous caesarean section, myomectomy, hysterotomy)

5. Non-reassuring fetal heart rate 462 women who were fulfilling the inclusion criteria were recruited for the study. With the help of random number generator table they were randomised in two groups. Women belonging to group A received misoprostol vaginally $50 \mathrm{mcg}$ every 4hourly $(n=231)$ while group $B$ received misoprostol sublingually 50 mcg every 4 hourly $(\mathrm{n}=231)$. In sublingual group, the tablet was placed under the tongue while in vaginal group, the tablet was inserted into posterior fornix of the vagina. In both groups, administration of misoprostol was repeated every 4 hours until regular uterine contractions were achieved, or woman had received a total of 4 doses. Prior to next dose administration, a fetal cardiotocography was performed for $20 \mathrm{~min}$ to confirm fetal wellbeing as well as per vaginal examination was done to assess the Bishop score. The subsequent dose was withheld in the presence of any of the following: at least three regular uterine contractions in 10 minutes, active phase of labour (defined as regular uterine contractions with cervical dilation $>3 \mathrm{~cm}$ ), cervix favourable for amniotomy (Bishop score 7,8). If frequency of contractions was $<3$ per 10 minutes or contraction pattern was dysfunctional, oxytocin infusion was administered not earlier than 4 hours after last misoprostol dose. Strict monitoring of heart rate and uterine activity was done for tachysystole, hypertonus and hyper stimulation syndrome. Uterine tachysystole was defined as six or more uterine contractions in $10 \mathrm{~min}$ while uterine hypertonus was defined as a single contraction lasting longer than 2 minutes. When either of above condition was associated with non reassuring fetal heart rate pattern, it was labelled as uterine hyper stimulation. All the episodes of hyperstimulation syndrome were included in the analysis regardless of the interval from the time of misoprostol administration to the occurrence of the abnormal fetal heart rate pattern. The primary outcome measure was the interval from the start of induction to vaginal delivery,. Secondary outcome variables included number of women delivering within 12 hours of induction, the number of misporstrol doses given, the need of oxytocin augmentation, the mode of delivery, uterine 
hyperstimulation rate and maternal adverse effects. Neonatal outcome in terms of Apgar score at 1 and $5 \mathrm{~min}$, meconium stained amniotic fluid were also evaluated.

\section{Statistical Analysis}

Descriptive and inferential statistical analysis has been carried out in the current study. Results on continuous measurements are presented on Mean $\square$ SD (Min-Max) and results on categorical measurements are presented in Number (\%).Tests of significance was analysed using Chi-square and student test. P-value $<0.05$ was taken as significant.

\section{Results}

Total 462 women were enrolled in the study which were randomized in 2 groups. Mean age of vaginal group was $27.42 \pm 3.9$ years while in sublingual group it was $25.2 \pm 4.3$ years( $\mathrm{p}$ value $>0.05$ ). Maximum number of patients belonged to the age group26-30years in both the groups whereas the least numbers of the patients were from the age group 36-40 years. $93.1 \%$ \& $91.4 \%$ women were normotensive in vaginal and sublingual group respectively. $6.9 \%$ \& $8.6 \%$ women in vaginal and sublingual group respectively were having pre-eclamptic toxaemia. However this difference was statistically non significant ( $\mathrm{p}$ value $>0.05$ ). The mean period of gestation was $277.55 \pm 3.944$ days in the vaginal group and $277.43 \pm 4.303$ days in sublingual ( $p$ value 0.761). Pre-induction Bishop Score was $3.436 \pm 0.736$ and $3.418 \pm 0.759$ in vaginal and sublingual group respectively(p value >0.05). Most common indication for induction was term pregnancy $(75.3 \%$ \& $71 \%$ in vaginal and sublingual group respectively). Other indications were post dated pregnancy ( $16.5 \%$ vs $19.5 \%)$, pre eclamptic toxaemia $(6.9 \%$ vs $8.6 \%)$ and $\mathrm{Rh}$ negative pregnancy $(1.3 \%$ vs $0.9 \%)$ in vaginal and sublingual group respectively. The difference was not statistically significant (p-0.72). Mean Bishop Score after 4 hours of first dose administration was $5.773 \pm 2.204$ and $4.827 \pm 2.237$ in vaginal and sublingual group respectively ( $\mathrm{p}$ value $<0.01$ ). The mean numbers of doses required were $1.48 \& 1.41$ respectively in vaginal and sublingual group ( $\mathrm{p}$ value $>0.05$ ). Oxytocin augmentation was required only in $6 \%$ patients in vaginal group as compared to $15 \%$ in sublingual group ( $\mathrm{p}$ value $=0.005$ ). Mean induction to delivery time interval in vaginal group was $11.85 \pm 6.685$ hours while in sublingual group it was $10.66 \pm 5.48$ hours (p value $>0.05$ ). $92.2 \%$ women in vaginal group and $84.7 \%$ women in sublingual group delivered within 24 hours of induction. This difference was statistically insignificant ( $p$-value $=0.34$ ). Outcome of induction in term of requirement of caesarean section was comparable in both the groups. 11.7 $\%$ women in vaginal group and \& $12.1 \%$ in sublingual group underwent caesarean section ( $\mathrm{p}$ value0.81). Fetal distress was the commonest indication for caesarean section. 3.5\% women in vaginal group compared to $6.9 \%$ in sublingual group underwent caesarean section due to fetal distress ( $\mathrm{p}$ value 0.18). 2.6\% women in vaginal group and $7.8 \%$ women in sublingual group had meconium stained liquor ( $\mathrm{p}-0.48)$.

The mean neonatal birth weight in the sublingual group was $3.06 \pm 0.4 \mathrm{~kg}$ while in the vaginal group, it was $3.02 \pm 0.4 \mathrm{~kg}$. Both the groups were comparable and there was no statistical difference between the neonatal weight in both the groups ( $p$ value $=0.246$ ). Mean Apgar score at 1 minute was $8.864 \pm 0.735$ and $8.836 \pm 0.736$ in vaginal \& sublingual group respectively ( $\mathrm{p}$ value $>0.05$ ). Very few maternal complications occurred in form of uterine hyper stimulation in $2.6 \% \quad \& 3.5 \%$ women in vaginal and sublingual group respectively. $3.5 \%$ women in vaginal group developed PPH as compared $2.16 \%$ women in sublingual group. None of women in vaginal group experienced vomiting while $3.5 \%$ women in sublingual group developed vomiting. 
Table 1: Main characteristics of two groups

\begin{tabular}{|c|c|c|c|c|}
\hline \multicolumn{2}{|l|}{ Variable } & Vaginal Group(n=231) & SublingualGroup $(\mathrm{n}=231)$ & P value \\
\hline \multicolumn{2}{|c|}{ Mean age(Years) } & $27.42 \pm 3.9$ & $25.2 \pm 4.3$ & $>0.05$ \\
\hline \multirow{2}{*}{$\begin{array}{l}\text { Blood } \\
\text { Pressure }\end{array}$} & Normotensive & $93.1 \%$ & $91.4 \%$ & \multirow{2}{*}{0.90} \\
\hline & $\begin{array}{l}\text { Pre-Eclamptic } \\
\text { Toxemia }\end{array}$ & $6.9 \%$ & $8.6 \%$ & \\
\hline \multicolumn{2}{|c|}{ Mean Period of gestation(Days) } & $277.55 \pm 3.944$ & $277.43 \pm 4.303$ & 0.761 \\
\hline \multicolumn{2}{|c|}{ Pre-induction Bishop Score } & $3.436 \pm 0.736$ & $3.418 \pm 0.759$ & $>0.05$ \\
\hline \multirow{4}{*}{$\begin{array}{l}\text { Indication for } \\
\text { Induction }\end{array}$} & Term pregnancy & $174(75.3 \%)$ & $164(71.0 \%)$ & \multirow{4}{*}{0.72} \\
\hline & $\begin{array}{l}\text { Pre-Eclamptic } \\
\text { Toxemia }\end{array}$ & $16(6.9 \%)$ & $20(8.6 \%)$ & \\
\hline & Post Dated & $38(16.5 \%)$ & $45(19.5 \%)$ & \\
\hline & $\begin{array}{l}\text { Rh negative } \\
\text { pregnancy }\end{array}$ & $3(1.3 \%)$ & $2(0.9 \%)$ & \\
\hline
\end{tabular}

Table 2: Outcome characteristic in both groups

\begin{tabular}{|c|c|c|c|c|}
\hline \multicolumn{2}{|l|}{ Variable } & Vaginal group $(n=231)$ & Sublingual Group $(n=231)$ & $\mathrm{P}$ value \\
\hline \multicolumn{2}{|c|}{ Mean Bishop Score after 4 hours } & $5.773 \pm 2.204$ & $4.827 \pm 2.237$ & $<0.01$ \\
\hline \multicolumn{2}{|c|}{ Mean dose required } & 1.48 & 1.41 & $>0.05$ \\
\hline \multicolumn{2}{|c|}{ Mean induction to delivery interval (Hrs) } & $11.85 \pm 6.685$ & $10.66 \pm 5.48$ & 0.053 \\
\hline \multicolumn{2}{|c|}{ Delivery within 24 hours } & $188(92.2 \%)$ & $172(84.7 \%)$ & 0.34 \\
\hline \multirow[t]{3}{*}{ Mode of delivery } & SVD & $182(78.8 \%)$ & $177(76.6 \%)$ & \multirow[t]{3}{*}{0.81} \\
\hline & ID & $22(9.5 \%)$ & $26(11.3 \%)$ & \\
\hline & $\mathrm{CS}$ & $27(11.7 \%)$ & $28(12.1 \%)$ & \\
\hline \multirow[t]{4}{*}{ Indication of CS } & $\mathrm{CD}$ & $7(3.0)$ & $7(3.0)$ & \multirow[t]{4}{*}{0.18} \\
\hline & FD & $8(3.5)$ & $16(6.9)$ & \\
\hline & FI & $7(3.0)$ & $4(1.7)$ & \\
\hline & POP & $5(2.2)$ & $1(0.9)$ & \\
\hline \multicolumn{2}{|c|}{$\begin{array}{l}\text { Requirement of } \quad \text { Oxytocin } \\
\text { Augmentation }\end{array}$} & $14(6 \%)$ & $35(15.1 \%)$ & 0.005 \\
\hline \multicolumn{2}{|c|}{ Meconium stained liquor } & $6(2.6 \%)$ & $18(7.8 \%)$ & 0.48 \\
\hline \multicolumn{2}{|c|}{ Mean Birth weight } & $3.02 \pm 0.4$ & $3.06 \pm 0.4 \mathrm{~kg}$ & 0.246 \\
\hline \multicolumn{2}{|c|}{ Mean APGAR @1 minute } & $8.864 \pm 0.735$ & $8.836 \pm 0.736$ & $>0.05$ \\
\hline \multirow{3}{*}{$\begin{array}{l}\text { Maternal } \\
\text { complications }\end{array}$} & $\mathrm{PPH}$ & $8(3.5 \%)$ & $5(2.16 \%)$ & \multirow[t]{3}{*}{0.10} \\
\hline & Hyperstimulation & $6(2.6 \%)$ & $8(3.5 \%)$ & \\
\hline & Vomiting & $0(0.0)$ & $8(3.5 \%)$ & \\
\hline
\end{tabular}

SVD-Spontaneous vaginal delivery ID-Instrumental delivery CS- Caesarean section CD- Cervical Dystocia

FD-Fetal distress FI- Failed induction POP- persistence occipital posterior position PPH- Post partum Haemorrhage

\section{Discussion}

Misoprostol is a promosing prostaglandin which is frequently used for inducing abortion, management of PPH and induction of labour. However there are issues regarding FDA approval of the drug for use in labour induction owing to risk of uterine rupture, still it has gained popularity as it is cheap and easily available. Various studies have shown that both sublingual and oral route has quicker onset of action. ${ }^{7}$ Sublingual route may be preferred in case of rupture of membrane as vaginal route may not be effective due to wash away effect of liquor on misaprostol.
In the current study the base line characteristics were comparable in both the groups in term of mean age, mean gestational period, blood pressure, pre induction Bishop Score and indication for induction. These observations are similar to the result observed by Shetty et al. ${ }^{8}$

More women in vaginal group delivered within 24 hours after induction as compared to sublingual route, however this difference was statistically non significant. Souza $\mathrm{S}$ et $\mathrm{al}^{2}$ in their study found no statistically significant difference between the sublingual and the vaginal misoprostol groups with respect to the rate of vaginal delivery within 24 hours. 
Mean induction to delivery interval was slightly higher in vaginal group as compared to sublingual group, however this difference was statistically non-significant ( $p>0.05)$.Similar results were observed in a study done by Caliskan $\mathrm{E}$ et al. ${ }^{3}$ No significant difference was observed in mean dose requirement between both the groups. However study done by Caliskan $\mathrm{E}$ et $\mathrm{al}^{3}$ has shown that the mean number of misoprostol doses required was significantly higher in the sublingual group (1.9 $+/-1.2)$ compared with the vaginal group $(1.1+/$ $0.4 ; \mathrm{p}<0.001)$.

No significant difference was noted between sublingual and vaginal group in incidence of caesarean section. Similar to the current study Eroglu DS et $\mathrm{al}^{9}$ found that both modalities had similar incidences of primary caesarean section Commonest indication of caesarean section was fetal distress in both the group. However the incidence of fetal distress was similar in both the groups. Ayati $\mathrm{S}$ et $\mathrm{al}^{10}$ had also observed fetal distress as a commonest indication of caesarean section with no statistically significant difference between both the groups.

Mean Bishop Score after 4 hours of induction was higher in vaginal group compared to sublingual group and this difference was statistically significant ( $\mathrm{p}$ value $<0.01$ ), it means that sublingual route may be slightly more effective for induction. Similarly vaginal group has required less oxytocin augmentation and this difference was also statistically significant (.005). In current study no significant difference between both the groups was observed in neonatal outcome in term of meconium stained liquor, birth weight and APGAR Score at 1 minute. Maternal complications were not significant in both the groups. No significant difference was found between both the with regards to incidence of maternal complications. Similar to our study Ayati $\mathrm{S}$ et $\mathrm{al}^{10}$ had also found no statistically significant difference between vaginal and sublingual group with regards to fetal outcomes and maternal complications.

\section{Conclusion}

In the present study, sublingual and vaginal misoprostol showed similar effectiveness for induction of labour in unfavourable cervix. However lesser women in vaginal group required oxytocin augmentation but as administration by sublingual route avoids repeated vaginal examination, this significant difference can be overlooked. Only few patients had minor side effects in both groups.

\section{References}

1. Managing complications in pregnancy and childbirth: a guide for midwives and doctors. Geneva, World Health Organisation, 2000

2. Souza AS, Amorim MM, Feitosa FE. Comparison of sublingual versus vaginal misoprostol for the induction of labour: a systematic review. BJOG. 2008; 115: 1340 -1349 .

3. Caliskan E, Bodur H, Ozeren S, Corakci A, Ozkan S, Yucesoy I. Misoprostol $50 \mu \mathrm{g}$ sublingually versus vaginally for labor induction at term: a randomized study. Gynecologic and Obstetric Investigation. 2005;59(3):155-61.

4. Bartusevicius A, Barcaite E, Krikstolaitis R, Gintautas V, Nadisauskiene R. Sublingual compared with vaginal misoprostol for labour induction at term: a randomised controlled trial. Int $\mathrm{J}$ Obstet Gynaecol. 2006;113(12):1431-7.

5. Nassar AH, Awwad J, Khalil AM, Abu-Musa A, Mehio G, Usta IM. A randomized comparison of patient satisfaction with vaginal and sublingual misoprostol for induction of labour at term. Int J Obstet Gynaecol. 2007;114(10):1215-21.

6. Zahran KM, Shahin AY, Abdellah MS, Elsayh KI. Sublingual versus vaginal misoprostol for induction of labor at term: A randomized prospective placebo- 
controlled study. J Obstet Gynaecol Res. 2009;35(6):1054-60

7. Zieman M, Fong S, Benowitz N, Banskter D, Darney P. Absorption kinetics of misoprostol with oral or vaginal administration. Obstet Gynecol 1997; 90(1):88-92.

8. Shetty A, Danilien P, Templeton A. A comparison of oral and vaginal misoprostol in induction of labor at term. Br J Obstet Gynaecol. 2001;108:218-24.

9. Eroglu D, Oktem M, Yanik F, Kuscu E. Labour induction at term: A comparison of the effects of $50 \mathrm{mcg}$ and $25 \mathrm{mcg}$ vaginal misoprostol. Clin Exp Obstet Gynaecol 2007;34(2):102-5.

10. Ayati S, Vahidroodsari F, Farshidi F, Shahabian M, Afzal Aghaee M. Vaginal versus sublingual misoprostol for labour induction at term and post term. Iran $\mathrm{J}$ Pharm Res 2014;13(1):299-304. 